\title{
SISTEM PENDUKUNG KEPUTUSAN PEMILIHAN PENGGUNAAN JENIS TANAMAN DENGAN METODE ANALYTIC HIERARCHY PROCESS (AHP)
}

\author{
Nur Musyarrofatul Mala ${ }^{1}$, Anton Muhibuddin ${ }^{2}$, Agus Sifaunajah ${ }^{3}$ \\ 1) Program Studi Sistem Informasi Universitas KH. A. Wahab Hasbullah \\ 2) Fakultas Pertanian Universitas Brawijaya \\ 3) Program Studi Ilmu Komputer Universitas KH. A. Wahab Hasbullah
}

Correspondence Author: agus.syifa85@gmail.com

\begin{abstract}
ABSTRAK
Bidang Pertanian merupakan sektor penting yang tidak dapat dipisahkan dalam menentukan pembentukan berbagai realitas ekonomi dan sosial masyarakat di berbagai wilayah Indonesia. Sebagian besar mata pencaharian masyarakat Indonesia adalah dilingkup pertanian. Dalam kehidupan sehari hari bagi para petani masih terdapat berbagai masalah atau kendala misalnya kegagalan panen karena lahan yang kurang cocok untuk pertumbuhan tanaman, ketidakpastian iklim dan lain-lain. Sehingga dalam hal ini akan dibuat sistem informasi yang akan memberikan rekomendasi bagi para petani dalam menentukan penggunaan jenis tanaman yang sesuai dengan kondisi lahan pada daerah tertentu.

Aplikasi ini menggunakan Analytic Hierarchy Process (AHP) sebagai metode yang akan mengambil keputusan dari beberapa kriteria dengan menghitung perbandingan bobot atau nilai pada masing-masing jenis tanaman dan akan menghasilkan informasi berupa peringkat tanaman yang direkomendasikan. Sehingga sistem pendukung keputusan dengan metode AHP ini dapat dijadikan sebagai salah satu solusi dalam menyelesaikan permasalahan pemilihan penggunaan tanaman yang sesuai dengan kondisi lahan pada daerah tertentu.
\end{abstract}

Kata Kunci : Analytic Hierarchy Process (AHP), Sistem Pendukung Keputusan, Kesesuaian Lahan

\begin{abstract}
Agriculture is an important sector that can not be separated in determining the formation of various economic and social reality of society in various regions of Indonesia. Most of the livelihoods of the Indonesian community are covered by agriculture. In daily life for farmers there are still many problems or constraints such as crop failure due to less suitable land for plant growth, climate uncertainty and others. So in this case will be made information system that will provide recommendations for farmers in determining the use of plant species in accordance with the conditions of land in certain areas.

This application use the Analytic Hierarchy Process (AHP) as a method that will take the decision of some criteria by calculating the weight ratio or value on each type of plant and will produce information in the form of cropratings are recommended. So that decision support system with AHP method can be used as one solution in solving the problem of choosing the use of plants in accordance with the condition of the land in certain areas.
\end{abstract}

Keywords: Analytic Hierarchy Process (AHP), Decision Support System, Land Suitability 


\section{Pendahuluan}

\subsection{Latar Belakang}

Banyak bidang yang memanfaatkan sistem pendukung keputusan dalam menyelesaikan dan memberikan solusi dari sebuah masalah untuk mendapatkan hasil yang terbaik dari berbagai pilihan. Salah satunya yaitu bidang pertanian. Bidang Pertanian merupakan sektor penting yang tidak dapat dipisahkan dalam menentukan pembentukan berbagai realitas ekonomi dan sosial masyarakat di berbagai wilayah Indonesia. Sebagian besar mata pencaharian masyarakat Indonesia adalah dilingkup pertanian. Dalam kehidupan sehari hari bagi para petani masih terdapat berbagai masalah atau kendala misalnya kegagalan panen karena lahan yang kurang cocok untuk pertumbuhan tanaman, ketidakpastian iklim dan lain-lain. Sehingga dalam hal ini akan dibuat sistem informasi yang akan memberikan rekomendasi bagi para petani dalam menentukan penggunaan jenis tanaman yang sesuai dengan kondisi lahan pada daerah tertentu.

Aplikasi ini akan menggunakan Analytic Hierarchy Process (AHP) sebagai metode yang akan mengambil keputusan dari beberapa kriteria dengan menghitung perbandingan bobot atau nilai pada masing-masing jenis tanaman dan akan menghasilkan informasi berupa peringkat tanaman yang direkomendasikan.

\section{Kerangka Teori}

\subsection{Sistem Pendukung Keputusan/ Decision Support System (DSS)}

DSS merupakan sistem informasi interaktif yang menyediakan informasi, pemodelan, dan pemanipulasian data. Sistem itu digunakan untuk membantu pengambilan keputusan dalam situasi yang semiterstruktur dan situasi yang tidak terstruktur, di mana tak seorang pun tahu secara pasti bagaimana keputusan seharusnya dibuat (Alter, 2002).

DSS biasanya dibangun untuk mendukung solusi atau suatu masalah atau untuk mengevaluasi suatu peluang. DSS yang seperti itu disebut aplikasi DSS. Aplikasi DSS digunakan dalam pemngambilan keputusan. Aplikasi DSS menggunakan CBIS (Computer Based Information Systems) yang fleksibel, interaktif, dan dapat diadaptasi, yang dikembangkan untuk mendukung solusi atas masalah manajemen spesifik yang tidak terstruktur.

Menurut Simon (1977), otak manusia memiliki kemampuan yang terbatas untuk memproses dan menyimpan informasi. Orang-orang kadang sulit mengingat dan menggunakan sebuah informasi dengan cara yang bebas dari kesalahan.

\subsection{Model Analytical Hierarkhi Process (AHP)}

Pada dasarnya, proses pengambilan keputusan adalah memilih suatu alternatif. Peralatan utama AHP adalah sebuah hierarki fungsional dengan input utamanya persepsi manusia. Keberadaan hierarki memungkinkan dipecahnya masalah kompleks atau tidak terstruktur dalam sub-sub masalah, lalu menyusunnya menjadi suatu bentuk hierarki.

AHP memiliki banyak keunggulan dalam menjelaskan proses pengambilan keputusan. Salah satunya adalah dapat digambarkan secara grafis sehingga mudah dipahami oleh semua pihak yang terlibat dalam pengambilan keputusan.

\subsubsection{Prinsip Dasar AHP}

Dalam menyelesaikan permasalahan dengan AHP ada beberapa prinsip yang harus dipahami, di antaranya adalah:

1. Membuat hierarki

Sistem yang kompleks bisa dipahami dengan memecahnya menjadi elemen-elemen pendukung, menyusun elemen secara hierarki, dan menggabungkannya atau mensintesisnya.

2. Penilaian kriteria dan alternative

Kriteria dan alternatif dilakukan dengan perbandingan berpasangan. Menurut Saaty (1988), untuk berbagai persoalan, skala 1 sampai 9 adalah skala terbaik untuk 
mengekspresikan pendapat. Nilai dan definisi pendapat kualitatif dari skala perbandingan Saaty bisa diukur menggunakan tabel analisis seperti ditunjukkan pada Tabel 2.1 berikut.

Tabel 1. Skala Penilaian Perbandingan Pasangan

\begin{tabular}{|c|l|}
\hline $\begin{array}{c}\text { Intensitas } \\
\text { Kepentingan }\end{array}$ & \multicolumn{1}{c|}{ Keterangan } \\
\hline 1 & Kedua elemen sama pentingnya \\
\hline 3 & Elemen yang satu sedikit lebih penting daripada elemen yang lainnya \\
\hline 5 & Elemen yang satu lebih penting daripada elemen lainnya \\
\hline 7 & Satu elemen jelas lebih mutlak penting daripada elemen lainnya \\
\hline 9 & Satu elemen mutlak penting daripada elemen lainnya \\
\hline $2,4,6,8$ & Nilai-nilai antara dua nilai pertimbangan yang berdekatan \\
\hline Kebalikan & $\begin{array}{l}\text { Jika aktivitas i mendapat satu angka dibandingkan dengan aktivitas } \mathrm{j}, \\
\text { maka j memiliki nilai kebalikannya dibandingkan dengan i }\end{array}$ \\
\hline
\end{tabular}

3. Synthesis of priority (menentukan prioritas)

Untuk setiap kriteria dan alternatif, perlu dilakukan perbandingan berpasangan (pairwise Comparisons). Nilai-nilai perbandingan relatif dari seluruh alternatif kriteria bisa disesuaikan dengan judgement yang telah ditentukan untuk menghasilkan bobot dan prioritas. Bobot dan prioritas dihitung dengan memanipulasi matriks atau melalui penyelesaian persamaan matematika.

4. Logical Consistency (Konsistensi Logis)

Konsistensi memiliki dua makna. Pertama, objek-objek yang serupa bisa dikelompokkan sesuai dengan keseragaman dan relevansi. Kedua, menyangkut tingkat hubungan antarobjek yang didasarkan pada kriteria tertentu.

\section{Hasil dan Pembahasan}

\subsection{Implementasi Sistem}

Dalam sub bab ini, penulis akan menjelaskan beberapa hal mengenai implementasi sistem atau aplikasi Sistem Pendukung Keputusan Pemilihan Penggunaan Jenis Tanaman. Berikut implementasinya :

\subsubsection{Form Menu Input Data Lahan}

Form ini digunakan untuk menginputkan data lahan pada kriteria yang sudah disediakan seperti terlihat dibawah ini :

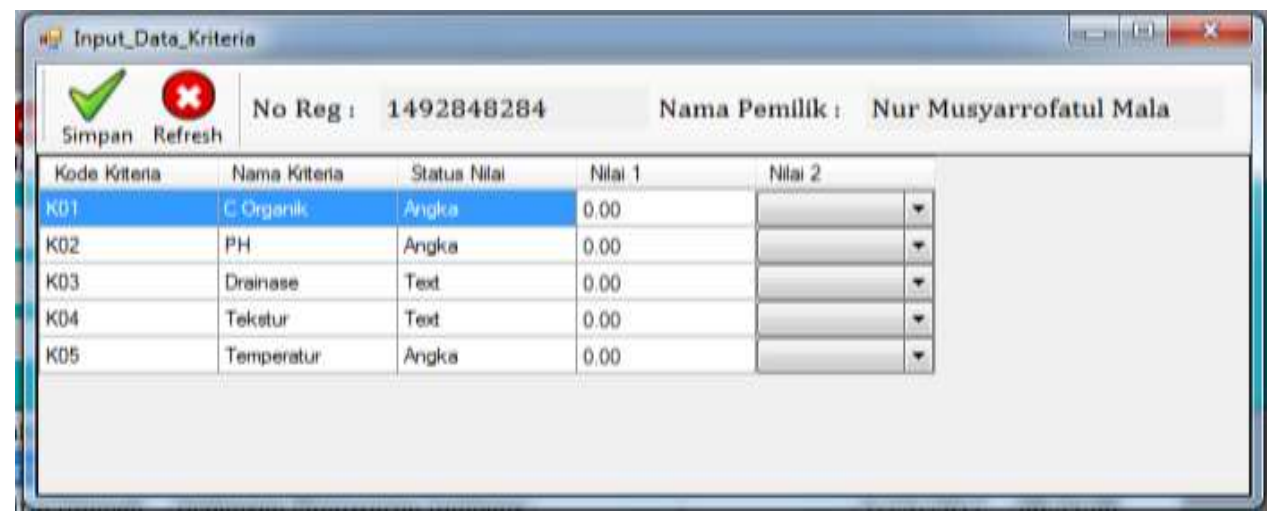

Gambar 1: Form Input Data Lahan 


\subsubsection{Form Hasil}

Form ini digunakan untuk menampilkan hasil rangking yang dirancang seperti terlihat dibawah ini :

\begin{tabular}{|l|l|l|l|l|}
\hline No Reg: & 1492911248 & Nama Pemilik: & Eliana Khoirul Ummah \\
\hline id_tanaman & nama_tanaman & bobot_prioritas & \\
\hline T03 & Kacang Tanah & 1.76 & \\
\hline T02 & Jagung & 0.92 & \\
\hline T01 & Padi & 0.44 & \\
\hline & & & \\
\hline
\end{tabular}

\section{Gambar 2 : Form Hasil}

\subsection{Metode Perhitungan Analytic Hierarchy Process (AHP)}

Dalam pembahasan ini mengenai metode perhitungan Analytic Hierarchy Process (AHP). Adapun metode perhitungannya akan dibahas oleh penulis, adalah sebagai berikut :

1. Menentukan Prioritas Kriteria

a. Membuat matriks perbandingan berpasangan

Pada tahap ini dilakukan penilaian perbandingan antara satu kriteria dengan yang lain.

Tabel 2. Matriks Perbandingan Berpasangan

\begin{tabular}{|l|c|c|c|c|c|}
\hline & Temperatur & Tekstur & Drainase & PH & C Organik \\
\hline Temperatur & 1.00 & 2.00 & 2.00 & 3.00 & 5.00 \\
\hline Tekstur & 0.50 & 1.00 & 3.00 & 2.00 & 3.00 \\
\hline Drainase & 0.50 & 0.33 & 1.00 & 2.00 & 3.00 \\
\hline PH & 0.33 & 0.50 & 0.50 & 1.00 & 2.00 \\
\hline C Organik & 0.20 & 0.33 & 0.33 & 0.50 & 1.00 \\
\hline Jumlah & 2.53 & 4.17 & 6.83 & 8.50 & 14.00 \\
\hline
\end{tabular}

Angka 1 pada kolom temperatur baris temperatur menggambarkan tingkat kepentingan yang sama antara temperatur dengan temperatur, sedangkan angka 2 pada kolom tekstur baris temperatur menunjukkan tekstur sedikit lebih penting dibandingkan dengan temperatur. Angka 0.50 pada kolom temperatur baris tekstur merupakan hasil perhitungan 1/nilai pada kolom tekstur baris temperature (2). Angka-angka yang lain diperoleh dengan cara yang sama.

b. Membuat matriks nilai kriteria

Hasil perhitungan bisa dilihat dalam Tabel 3.

Tabel 3. Matriks Nilai Kriteria

\begin{tabular}{|l|c|c|c|c|c|c|c|}
\hline & Temperatur & Tekstur & Drainase & PH & C Organik & Jumlah & Prioritas \\
\hline Temperatur & 0.39 & 0.48 & 0.29 & 0.35 & 0.36 & 1.88 & 0.38 \\
\hline Tekstur & 0.20 & 0.24 & 0.44 & 0.24 & 0.21 & 1.33 & 0.27 \\
\hline Drainase & 0.20 & 0.08 & 0.15 & 0.24 & 0.21 & 0.87 & 0.17 \\
\hline PH & 0.13 & 0.12 & 0.07 & 0.12 & 0.14 & 0.59 & 0.12 \\
\hline C Organik & 0.08 & 0.08 & 0.05 & 0.06 & 0.07 & 0.34 & 0.07 \\
\hline
\end{tabular}


Nilai 0.39 pada kolom temperatur baris temperatur Tabel 3. diperoleh dari nilai kolom temperatur baris temperatur Tabel 2. dibagi jumlah kolom temperatur Tabel 2. Nilai kolom jumlah pada Tabel 3. diperoleh dari penjumlahan pada setiap barisnya. Nilai pada kolom prioritas diperoleh dari nilai pada kolom jumlah dibagi dengan jumlah kriteria.

c. Membuat matriks penjumlahan setiap baris

Matriks ini dibuat dengan mengalikan nilai prioritas pada Tabel 3. dengan matriks perbandingan berpasangan (Tabel 2.).

Tabel 4. Matriks Penjumlahan Setiap Baris

\begin{tabular}{|l|c|c|c|c|c|c|}
\hline & Temperatur & Tekstur & Drainase & PH & C Organik & Jumlah \\
\hline Temperatur & 0.38 & 0.53 & 0.35 & 0.35 & 0.34 & 1.94 \\
\hline Tekstur & 0.19 & 0.27 & 0.52 & 0.23 & 0.20 & 1.41 \\
\hline Drainase & 0.19 & 0.09 & 0.17 & 0.23 & 0.20 & 0.89 \\
\hline PH & 0.13 & 0.13 & 0.09 & 0.12 & 0.14 & 0.60 \\
\hline C Organik & 0.08 & 0.09 & 0.06 & 0.06 & 0.07 & 0.35 \\
\hline
\end{tabular}

Nilai 0.38 pada kolom temperatur baris temperatur Tabel 4. diperoleh dari prioritas baris temperatur pada Tabel 3. (0.38) dikalikan dengan nilai baris temperatur kolom temperatur pada Tabel 2.

Kolom jumlah pada table 4. diperoleh dengan menjumlahkan nilai pada masing-masing baris pada table tersebut.

d. Penghitungan rasio konsistensi

Penghitungan ini digunakan untuk memastikan bahwa nilai rasio konsistensi $(\mathrm{CR})<=0.1$. Jika ternyata nilai CR lebih besar dari 0.1 maka matriks perbandingan berpasangan harus diperbaiki.

Tabel 5. Perhitungan Rasio Konsistensi

\begin{tabular}{|l|c|c|c|}
\hline & Jumlah per baris & Prioritas & Hasil \\
\hline Temperatur & 1.94 & 0.38 & 2.32 \\
\hline Tekstur & 1.41 & 0.27 & 1.68 \\
\hline Drainase & 0.89 & 0.17 & 1.06 \\
\hline PH & 0.60 & 0.12 & 0.71 \\
\hline C Organik & 0.35 & 0.07 & 0.42 \\
\hline
\end{tabular}

Kolom jumlah per baris diperoleh dari kolom jumlah pada Tabel 4, sedangkan kolom prioritas diperoleh dari kolom prioritas pada Tabel 3.

Dari Tabel 5, diperoleh nilai-nilai sebagai berikut :

Jumlah (jumlahan dari nilai-nilai hasil) : 6.19

$\mathrm{n}$ (jumlah kriteria) : 5

$\lambda$ maks (jumlah $/ \mathrm{n}): 1.24$

CI $((\lambda$ maks $-\mathrm{n}) / \mathrm{n}):-0.75$

$\mathrm{CR}=(\mathrm{CI} / \mathrm{IR}):-0.75 / 1.12=-0.67$

Oleh karena $\mathrm{CR}<0.1$, maka rasio konsistensi dari perhitungan tersebut bisa diterima.

a. Menentukan prioritas sub kriteria. Menghitung prioritas subkriteria dari kriteria temperature.

$\checkmark$ Membuat matriks perbandingan berpasangan 
Tabel 6. Matriks Perbandingan Berpasangan Kriteria Temperatur

\begin{tabular}{|l|c|c|c|}
\hline & Sangat Sesuai & Cukup Sesuai & Sesuai Marjinal \\
\hline Sangat Sesuai & 1.00 & 2.00 & 3.00 \\
\hline Cukup Sesuai & 0.50 & 1.00 & 2.00 \\
\hline Sesuai Marjinal & 0.33 & 0.50 & 1.00 \\
\hline Jumlah & 1.83 & 3.50 & 6.00 \\
\hline
\end{tabular}

$\checkmark$ Membuat matriks nilai kriteria

Tabel 7. Matriks Nilai Kriteria Temperatur

\begin{tabular}{|l|c|c|c|c|c|c|}
\hline & $\begin{array}{c}\text { Sangat } \\
\text { Sesuai }\end{array}$ & $\begin{array}{c}\text { Cukup } \\
\text { Sesuai }\end{array}$ & Sesuai Marjinal & Jumlah & Prioritas & $\begin{array}{c}\text { Prioritas } \\
\text { Subkriteria }\end{array}$ \\
\hline Sangat Sesuai & 0.55 & 0.57 & 0.50 & 1.62 & 0.54 & 1.00 \\
\hline Cukup Sesuai & 0.27 & 0.29 & 0.33 & 0.89 & 0.30 & 0.55 \\
\hline Sesuai Marjinal & 0.18 & 0.14 & 0.17 & 0.49 & 0.16 & 0.30 \\
\hline
\end{tabular}

Menentukan matriks penjumlahan setiap baris

Tabel 8. Matriks Penjumlahan Setiap Baris Kriteria Temperatur

\begin{tabular}{|l|c|c|c|c|}
\hline & Sangat Sesuai & $\begin{array}{c}\text { Cukup } \\
\text { Sesuai }\end{array}$ & $\begin{array}{c}\text { Sesuai } \\
\text { Marjinal }\end{array}$ & Jumlah \\
\hline Sangat Sesuai & 0.54 & 0.59 & 0.49 & 1.62 \\
\hline Cukup Sesuai & 0.27 & 0.30 & 0.33 & 0.89 \\
\hline Sesuai Marjinal & 0.18 & 0.15 & 0.16 & 0.49 \\
\hline
\end{tabular}

Penghitungan rasio konsistensi

Tabel 9. Penghtungan Rasio Konsistensi

\begin{tabular}{|l|c|c|c|}
\hline & Jumlah Per Baris & Prioritas & Hasil \\
\hline Sangat Sesuai & 1.62 & 0.54 & 2.16 \\
\hline Cukup Sesuai & 0.89 & 0.30 & 1.19 \\
\hline Sesuai Marjinal & 0.49 & 0.16 & 0.66 \\
\hline
\end{tabular}

Jumlah (jumlahan dari nilai-nilai hasil): 4.01

n (jumlah kriteria) : 3

$\lambda$ maks (jumlah/n) $: 1.34$

CI $((\lambda$ maks $-\mathrm{n}) / \mathrm{n}):-0.55$

$\mathrm{CR}=(\mathrm{CI} / \mathrm{IR}):-0.55 / 0.58=-0.96$

b. Menghitung prioritas subkriteria dari kriteria tekstur Langkah-langkahnya adalah sebagai berikut :

$\checkmark$ Membuat matriks perbandingan berpasangan

Tabel 10. Matriks Perbandingan Berpasangan Kriteria Tekstur

\begin{tabular}{|l|c|c|c|}
\hline & Sangat Sesuai & Cukup Sesuai & Sesuai Marjinal \\
\hline Sangat Sesuai & 1.00 & 2.00 & 4.00 \\
\hline Cukup Sesuai & 0.50 & 1.00 & 2.00 \\
\hline Sesuai Marjinal & 0.25 & 0.50 & 1.00 \\
\hline Jumlah & 1.75 & 3.50 & 7.00 \\
\hline
\end{tabular}


Membuat matriks nilai kriteria

Tabel 11. Matriks Nilai Kriteria Tekstur

\begin{tabular}{|l|c|c|c|c|c|c|}
\hline & $\begin{array}{c}\text { Sangat } \\
\text { Sesuai }\end{array}$ & $\begin{array}{c}\text { Cukup } \\
\text { Sesuai }\end{array}$ & $\begin{array}{c}\text { Sesuai } \\
\text { Marjinal }\end{array}$ & Jumlah & Prioritas & $\begin{array}{c}\text { Prioritas } \\
\text { Subkriteria }\end{array}$ \\
\hline Sangat Sesuai & 0.57 & 0.57 & 0.57 & 1.71 & 0.57 & 1.00 \\
\hline Cukup Sesuai & 0.29 & 0.29 & 0.29 & 0.86 & 0.29 & 0.50 \\
\hline Sesuai Marjinal & 0.14 & 0.14 & 0.14 & 0.43 & 0.14 & 0.25 \\
\hline
\end{tabular}

Matriks penjumlahan tiap-tiap baris

Tabel 12. Matriks Penjumlahan Setiap Baris Kriteria Tekstur

\begin{tabular}{|l|c|c|c|c|}
\hline & Sangat Sesuai & Cukup Sesuai & Sesuai Marjinal & Jumlah \\
\hline Sangat Sesuai & 0.57 & 0.57 & 0.57 & 1.71 \\
\hline Cukup Sesuai & 0.29 & 0.29 & 0.29 & 0.86 \\
\hline Sesuai Marjinal & 0.14 & 0.14 & 0.14 & 0.43 \\
\hline
\end{tabular}

Penghitungan rasio konsistensi

Tabel 13. Penghitungan Rasio Konsistensi Kriteria Tekstur

\begin{tabular}{|l|c|c|c|}
\hline & Jumlah Per Baris & Prioritas & Hasil \\
\hline Sangat Sesuai & 1.71 & 0.57 & 2.29 \\
\hline Cukup Sesuai & 0.86 & 0.29 & 1.14 \\
\hline Sesuai Marjinal & 0.43 & 0.14 & 0.57 \\
\hline
\end{tabular}

Jumlah (jumlahan dari nilai-nilai hasil): 4.00

n (jumlah kriteria) : 3

$\lambda$ maks (jumlah $/ \mathrm{n}): 1.33$

CI $((\lambda$ maks $-\mathrm{n}) / \mathrm{n}):-0.56$

$\mathrm{CR}=(\mathrm{CI} / \mathrm{IR}):-0.56 / 0.58=-0.96$

c. Menghitung prioritas subkrteria dari kriteria drainase

Langkah-langkahnya adalah sebagai berikut :

$\checkmark$ Membuat matriks perbandingan berpasangan

Tabel 14. Matriks Perbandingan Berpasangan Kriteria Drainase

\begin{tabular}{|l|c|c|c|}
\hline & Sangat Sesuai & Cukup Sesuai & Sesuai Marjinal \\
\hline Sangat Sesuai & 1.00 & 2.00 & 5.00 \\
\hline Cukup Sesuai & 0.50 & 1.00 & 2.00 \\
\hline Sesuai Marjinal & 0.20 & 0.50 & 1.00 \\
\hline Jumlah & 1.70 & 3.50 & 8.00 \\
\hline
\end{tabular}

Membuat matriks nilai kriteria

Tabel 15. Matriks Nilai Kriteria Drainase

\begin{tabular}{|l|c|c|c|c|c|c|}
\hline & $\begin{array}{c}\text { Sangat } \\
\text { Sesuai }\end{array}$ & $\begin{array}{c}\text { Cukup } \\
\text { Sesuai }\end{array}$ & $\begin{array}{c}\text { Sesuai } \\
\text { Marjinal }\end{array}$ & Jumlah & Prioritas & $\begin{array}{c}\text { Prioritas } \\
\text { Subkriteria }\end{array}$ \\
\hline Sangat Sesuai & 0.59 & 0.57 & 0.63 & 1.78 & 0.59 & 1.00 \\
\hline Cukup Sesuai & 0.29 & 0.29 & 0.25 & 0.83 & 0.28 & 0.46 \\
\hline Sesuai Marjinal & 0.12 & 0.14 & 0.13 & 0.39 & 0.13 & 0.22 \\
\hline
\end{tabular}

Matriks penjumlahan tiap-tiap baris

Tabel 16. Matriks Penjumlahan Setiap Baris Kriteria Drainase

\begin{tabular}{|l|c|c|c|c|}
\hline & Sangat Sesuai & Cukup Sesuai & Sesuai Marjinal & Jumlah \\
\hline Sangat Sesuai & 0.59 & 0.55 & 0.64 & 1.79 \\
\hline Cukup Sesuai & 0.30 & 0.28 & 0.26 & 0.83 \\
\hline Sesuai Marjinal & 0.12 & 0.14 & 0.13 & 0.39 \\
\hline
\end{tabular}


Penghitungan rasio konsistensi

Tabel 17. Penghitungan Rasio Konsistensi Kriteria Drainase

\begin{tabular}{|l|c|c|c|}
\hline & Jumlah Per Baris & Prioritas & Hasil \\
\hline Sangat Sesuai & 1.79 & 0.59 & 2.39 \\
\hline Cukup Sesuai & 0.83 & 0.28 & 1.11 \\
\hline Sesuai Marjinal & 0.39 & 0.13 & 0.51 \\
\hline
\end{tabular}

Jumlah (jumlahan dari nilai-nilai hasil): 4.01

$$
\begin{aligned}
& \mathrm{n}(\text { jumlah kriteria) }): 3 \\
& \lambda \text { maks }(\text { jumlah } / \mathrm{n}): 1.34 \\
& \mathrm{CI}((\lambda \text { maks }-\mathrm{n}) / \mathrm{n}):-0.55 \\
& \mathrm{CR}=(\mathrm{CI} / \mathrm{IR}):-0.55 / 0.58=-0.96
\end{aligned}
$$

d. Menghitung prioritas subkriteria dari kriteria $\mathrm{PH}$ Langkah-langkahnya adalah sebagai berikut :

$\checkmark$ Membuat matriks perbandingan berpasangan

Tabel 18. Matriks Perbandingan Berpasangan Kriteria PH

\begin{tabular}{|l|c|c|c|}
\hline & Sangat Sesuai & Cukup Sesuai & Sesuai Marjinal \\
\hline Sangat Sesuai & 1.00 & 2.00 & 6.00 \\
\hline Cukup Sesuai & 0.50 & 1.00 & 2.00 \\
\hline Sesuai Marjinal & 0.33 & 0.50 & 1.00 \\
\hline Jumlah & 1.83 & 3.50 & 9.00 \\
\hline
\end{tabular}

Membuat matriks nilai kriteria

Tabel 19. Matriks Nilai Kriteria PH

\begin{tabular}{|l|c|c|c|c|c|c|}
\hline & $\begin{array}{c}\text { Sangat } \\
\text { Sesuai }\end{array}$ & $\begin{array}{c}\text { Cukup } \\
\text { Sesuai }\end{array}$ & $\begin{array}{c}\text { Sesuai } \\
\text { Marjinal }\end{array}$ & Jumlah & Prioritas & $\begin{array}{c}\text { Prioritas } \\
\text { Subkriteria }\end{array}$ \\
\hline Sangat Sesuai & 0.55 & 0.57 & 0.67 & 1.78 & 0.59 & 1.00 \\
\hline Cukup Sesuai & 0.27 & 0.29 & 0.22 & 0.78 & 0.26 & 0.44 \\
\hline Sesuai Marjinal & 0.18 & 0.14 & 0.11 & 0.44 & 0.15 & 0.24 \\
\hline
\end{tabular}

Matriks penjumlahan tiap-tiap baris

Tabel 20. Matriks Penjumlahan Setiap Baris Kriteria PH

\begin{tabular}{|l|c|c|c|c|}
\hline & Sangat Sesuai & Cukup Sesuai & Sesuai Marjinal & Jumlah \\
\hline Sangat Sesuai & 0.59 & 0.52 & 0.87 & 1.99 \\
\hline Cukup Sesuai & 0.30 & 0.26 & 0.29 & 0.85 \\
\hline Sesuai Marjinal & 0.20 & 0.13 & 0.15 & 0.47 \\
\hline
\end{tabular}

Penghitungan rasio konsistensi

Tabel 21. Penghitungan Rasio Konsistensi Kriteria PH

\begin{tabular}{|l|c|c|c|}
\hline & Jumlah Per Baris & Prioritas & Hasil \\
\hline Sangat Sesuai & 1.99 & 0.59 & 2.58 \\
\hline Cukup Sesuai & 0.85 & 0.26 & 1.11 \\
\hline Sesuai Marjinal & 0.47 & 0.15 & 0.62 \\
\hline
\end{tabular}

Jumlah (jumlahan dari nilai-nilai hasil): 4.31

n (jumlah kriteria) : 3

$\lambda$ maks (jumlah/n) $: 1.44$

CI $((\lambda$ maks $-\mathrm{n}) / \mathrm{n}):-0.52$

$\mathrm{CR}=(\mathrm{CI} / \mathrm{IR}):-0.52 / 0.58=-0.90$ 
e. Menghitung prioritas subkriteria dari kriteria C Organik

Langkah-langkahnya adalah sebagai berikut :

$\checkmark$ Membuat matriks perbandingan berpasangan

Tabel 22. Matriks Perbandingan Berpasangan Kriteria C Organik

\begin{tabular}{|l|c|c|c|}
\hline & Sangat Sesuai & Cukup Sesuai & Sesuai Marjinal \\
\hline Sangat Sesuai & 1.00 & 2.00 & 7.00 \\
\hline Cukup Sesuai & 0.50 & 1.00 & 2.00 \\
\hline Sesuai Marjinal & 0.14 & 0.50 & 1.00 \\
\hline Jumlah & 1.64 & 3.50 & 10.00 \\
\hline
\end{tabular}

Membuat matriks nilai kriteria

Table 23. Nilai Kriteria C Organik

\begin{tabular}{|l|c|c|c|c|c|c|}
\hline & $\begin{array}{c}\text { Sangat } \\
\text { Sesuai }\end{array}$ & $\begin{array}{c}\text { Cukup } \\
\text { Sesuai }\end{array}$ & $\begin{array}{c}\text { Sesuai } \\
\text { Marjinal }\end{array}$ & Jumlah & Prioritas & $\begin{array}{c}\text { Prioritas } \\
\text { Subkriteria }\end{array}$ \\
\hline Sangat Sesuai & 0.61 & 0.57 & 0.70 & 1.88 & 0.63 & 1.00 \\
\hline Cukup Sesuai & 0.30 & 0.29 & 0.20 & 0.79 & 0.26 & 0.42 \\
\hline Sesuai Marjinal & 0.09 & 0.14 & 0.10 & 0.33 & 0.11 & 0.18 \\
\hline
\end{tabular}

$\checkmark$ Matriks penjumlahan tiap-tiap baris

Tabel 24. Matriks Penjumlahan Setiap Baris Kriteria C Organik

\begin{tabular}{|l|c|c|c|c|}
\hline & Sangat Sesuai & Cukup Sesuai & Sesuai Marjinal & Jumlah \\
\hline Sangat Sesuai & 0.63 & 0.53 & 0.77 & 1.92 \\
\hline Cukup Sesuai & 0.31 & 0.26 & 0.22 & 0.80 \\
\hline Sesuai Marjinal & 0.09 & 0.13 & 0.11 & 0.33 \\
\hline
\end{tabular}

Penghitungan rasio konsistensi

Tabel 25. Penghitungan Rasio Konsistensi Kriteria C Organik

\begin{tabular}{|l|c|c|c|}
\hline & Jumlah Per Baris & Prioritas & Hasil \\
\hline Sangat Sesuai & 1.92 & 0.63 & 2.55 \\
\hline Cukup Sesuai & 0.80 & 0.26 & 1.06 \\
\hline Sesuai Marjinal & 0.33 & 0.11 & 0.44 \\
\hline
\end{tabular}

Jumlah (jumlahan dari nilai-nilai hasil): 4.05

n (jumlah kriteria) $: 3$

$\lambda$ maks (jumlah/n) $: 1.35$

CI $((\lambda$ maks $-\mathrm{n}) / \mathrm{n}):-0.55$

$\mathrm{CR}=(\mathrm{CI} / \mathrm{IR}):-0.55 / 0.58=-0.95$

2. Menghitung hasil

Prioritas hasil perhitungan pada langkah 1 dan 2 kemudian dituangkan dalam matriks hasil yang terlihat dalam Tabel 26. .

Tabel 26. Matriks Hasil

\begin{tabular}{|l|c|c|c|c|}
\hline & Weight & Sangat Sesuai & Cukup Sesuai & Sesuai Marjinal \\
\hline Temperatur & 0.38 & 1.00 & 0.55 & 0.30 \\
\hline Tekstur & 0.27 & 1.00 & 0.50 & 0.25 \\
\hline Drainase & 0.17 & 1.00 & 0.46 & 0.22 \\
\hline PH & 0.12 & 1.00 & 0.44 & 0.24 \\
\hline C Organik & 0.07 & 1.00 & 0.42 & 0.18 \\
\hline
\end{tabular}




\section{KESIMPULAN DAN SARAN}

\subsection{Kesimpulan}

Sistem pendukung keputusan pemilihan penggunaan jenis tanaman dengan metode AHP ini dapat dijadikan sebagai salah satu solusi dalam menyelesaikan permasalahan pemilihan penggunaan jenis tanaman pada lahan tertentu menjadi lebih terstruktur dan terperinci. Dengan menerapkan 5 kriteria yang ada seperti C Organik, PH, drainase, tekstur, dan temperatur. Kesimpulan yang didapat pada penelitian ini adalah sebagai berikut :

1. Pengambilan keputusan untuk pemilihan penggunaan jenis tanaman ini menjadi lebih terstruktur dan terperinci agar petugas pertanian bisa lebih cepat dan mudah dalam mendapatkan hasil yang benar-benar sesuai tanaman yang cocok pada lahan tertentu.

2. Metode AHP ini mampu menjawab persoalan pemilihan penggunaan jenis tanaman yang bersifat multiple criteria.

\subsection{Saran}

Untuk pengembangan penelitian selanjutnya penulis menyarankan beberapa hal sebagai berikut :

1. Mengembangkan sistem ini secara online sehingga para pengambil keputusan bisa menginputkan data dan melihat hasil dari sistem ini dimanapun ia berada.

2. Mengembangkan system ini dengan menambahkan metode TOPSIS atau dengan metode lainnya untuk menyelesaikan permasalahan penentuan hasil rangking dengan lebih akurat dan terperinci.

3. Inputan data kriteria bisa dilakukan oleh sistem, sehingga data tersebut akan langsung masuk ke sistem tanpa harus dimasukkan oleh petugas pertanian. 


\section{DAFTAR PUSTAKA}

Alter. 2002. Analisis dan Perancangan Sistem Informasi dengan Metodologi Berorientasi Objek. Bandung : Informatika.

Aditya, Nur Alan. 2011. Jago PHP dan MySQL. Bekasi : Dunia Komputer.

Djaenudin, D. dkk. 2003. Kriteria Kesesuaian Lahan Untuk Komoditas Pertanian. Departemen Pertanian Balai Penelitian Tanah.

Hidayatullah, Priyanto. 2014. Visual Basic .NET Membuat Aplikasi Database dan Program Kreatif. Bandung : Informatika Bandung.

Kusrini, 2997. Konsep dan Aplikasi Sistem Pendukung Keputusan. Yogyakarta: Penerbit Andi.

Pratiwi, Intan. 2015. Sistem Pendukung Keputusan Pemilihan Rumput Terbaik Untuk Pembuatan Tamna Dengan Metode Analytical Hierarchy Process (AHP) . Skripsi S-1 . STMIK Budidarma Medan.

Saaty, T.L. 1988. Decision Making with Analytical Hierarchy Proces. International Journal services, Vol 1, No 1. Pittsburgh.

Turban, E., dkk. 2005. Decision Support Systems and Intelligent System Yogyakarta: Penerbit Andi.

Welda. 2006. Pemilihan Tanaman Pangan Unggulan Kotamadya Cilegon Menggunakan Analytical Hierarchy Process (AHP). Skripsi S-1. STMIK MDP Palembang. 